\title{
Aerodynamic Design and Analysis of High Performance Nozzles for Mach 4 Accelerator Vehicles
}

\author{
Nicholas J. Georgiadis ${ }^{*}$, Teryn W. DalBello", Charles J. Trefny ${ }^{\star}$, and Albert L. Johns ${ }^{\S}$ \\ NASA Glenn Research Center, Cleveland, OH 44135
}

\begin{abstract}
The aerodynamic design and performance analysis of two exhaust nozzles considered for use on a vehicle following an accelerating flight profile to a maximum flight speed corresponding to Mach 4.2 is presented. The vehicle operational requirements were set by the Air Vehicle Baseline Study commissioned by the Office of Naval Research. An afterburning engine cycle was assumed in the design and analysis process. The two nozzles investigated here were an axisymmetric convergent-divergent (C-D) nozzle with variable throat and exit area and an isentropic plug nozzle with variable throat area enabled by a translating outer cowl. Computational fluid dynamics was used to assist in the design process and to investigate the installed performance of the two nozzles at flight points from Mach 1.2 to Mach 4.2. For both nozzle configurations, the nozzles could not achieve perfectly expanded exit areas at the highest Mach numbers in order for the nozzle exit area to not exceed the vehicle cross sectional area. At the lower Mach numbers, the installed performance of the C-D nozzle was higher than that of the plug nozzle while at the highest Mach numbers, the performance of the two nozzles was similar.
\end{abstract}

\section{Nomenclature}

$\begin{array}{ll}\mathrm{A}_{8} & =\text { nozzle throat area } \\ \mathrm{A}_{9} & =\text { nozzle full expansion area } \\ \mathrm{C}_{\mathrm{fg}} & =\text { gross }(\text { or uninstalled) thrust coefficient }=\text { actual thrust } / \text { ideal thrust } \\ \mathrm{C}_{\mathrm{T}-\mathrm{D}} & =\text { installed thrust coefficient }=(\text { actual thrust }- \text { drag }) / \text { ideal thrust } \\ \mathrm{D}_{\max } & =\text { vehicle outer diameter }=19 \text { in } \\ \mathrm{NPR} & =\text { nozzle pressure ratio }=\text { nozzle stagnation pressure } / \text { freestream static pressure } \\ \mathrm{R}_{\max } & =\text { vehicle outer radius } \\ \mathrm{R}_{9} & =\text { nozzle exit radius corresponding to full expansion area } \\ \mathrm{y}^{+} & =\text {wall normal coordinate } \\ \theta & =\text { nozzle divergence angle }\end{array}$

\section{Introduction}

$\mathrm{T}$ HE design of an exhaust nozzle system for an aircraft having a supersonic cruise mission is typically optimized for a cruise condition and also must provide sufficient thrust performance at other important operating points such as takeoff and transonic conditions. In contrast, the exhaust nozzle system for a vehicle with an accelerating mission must provide optimal performance across the flight envelop as there is not a fixed cruise point where the aircraft operates the majority of the time.

\footnotetext{
* Aerospace Engineer, Propulsion Systems Division, Mail Stop 86-7, AIAA Associate Fellow

$\dagger$ Currently Senior Multi-disciplined Engineer, Raytheon Missile Systems Company

† Aerospace Engineer, Propulsion Systems Division, Mail Stop 86-7, AIAA Senior Member

$\S$ Aerospace Engineer, Propulsion Systems Division, Mail Stop 86-7
}

DISTRIBUTION STATEMENT A. Approved for public release December 21, 2005; distribution unlimited. 
In this paper, we present the aerodynamic design and performance evaluation of two exhaust nozzles that could be employed on a vehicle operating over a flight profile beginning with a subsonic launch and accelerating to a flight Mach number exceeding four. These requirements were set forth by the Air Vehicle Baseline (AVBL) study commissioned by the Office of Naval Research (ONR), relating to the Time Critical Strike mission. This flight profile is very similar to that considered by the NASA Revolutionary Turbine Accelerator (RTA) development effort (Ref. 1). A conceptual drawing of the AVBL is shown in Fig. 1. To achieve the higher flight speeds associated with this class of Mach 4 accelerator vehicles using a turbine engine, an afterburner most likely would be required. As a result, we utilize an afterburning turbine engine cycle in the nozzle design and analysis sequence described in this paper.

Nearly all combat aircraft in operation today employ a variable geometry axisymmetric convergentdivergent $(\mathrm{C}-\mathrm{D})$ nozzle which enables the required variation in nozzle throat area and exit area as a function of the nozzle pressure ratio schedule. The first nozzle considered here is such a C-D nozzle. The second nozzle considered in this work is an isentropic plug configuration. Isentropic plug nozzles have been considered for use with rocket propulsion systems (Refs. 2-4) but rarely have been considered for airbreathing propulsion system application. The plug nozzle concept offers potential advantages in terms of reduced weight and mechanical complexity relative to the $\mathrm{C}-\mathrm{D}$ nozzle. This is the result of the isentropic plug's capability to enable optimal nozzle expansion to the freestream pressure without variation in nozzle geometry.

In this paper, the axisymmetric C-D nozzle design and analysis sequence is provided first, followed by that for the isentropic plug. The Wind Reynolds-averaged Navier-Stokes (RANS) computational fluid dynamics (CFD) code is used to analyze the uninstalled and installed (including external nozzle drag effects) performance of the two configurations. CFD is also used in the design process to assist in the optimal determination of nozzle geometric characteristics.

\section{Design Constraints}

To meet overall AVBL packaging requirements, the outer diameter of the nozzles considered here could not exceed the vehicle outer diameter, $\mathrm{D}_{\max }=19 \mathrm{in}$. In addition, the total nozzle length, measured from the beginning of the convergent section to the nozzle exit at the end of the divergent section was restricted to not exceed 26 in. or 1.37 times the maximum outer vehicle diameter $\left(D_{\max }\right)$. As mentioned in the introduction, an afterburning engine cycle was assumed for use on the AVBL to meet mission requirements of acceleration to Mach 4.2. For the particular engine cycle utilized in this study, the nozzle pressure ratio (NPR), throat area $\left(A_{8}\right)$, and nozzle exit area $\left(A_{9}\right)$, are provided in Table 1 for engine operating points corresponding to flight conditions varying from Mach 1.2 to Mach 4.2. At the highest flight Mach numbers, the exit area required by the cycle deck to enable a perfectly expanded flow would exceed that of the AVBL cross section area. As a result, the nozzles considered here would be underexpanded at flight conditions of Mach 3 and higher. In Table 1, both the ideally expanded nozzle exit area and actual nozzle exit area are presented.

Table 1. Afterburning engine operating conditions.

\begin{tabular}{|c|c|c|c|c|}
\hline $\begin{array}{c}\text { Freestream } \\
\text { Mach Number }\end{array}$ & $\begin{array}{c}\text { Nozzle Pressure } \\
\text { Ratio (NPR) }\end{array}$ & $\begin{array}{c}\mathrm{A}_{8} \text { Throat Area } \\
\left(\mathrm{in}^{2}\right)\end{array}$ & $\begin{array}{c}\mathrm{A}_{9} \text { - ideal } \\
\left(\mathrm{in}^{2}\right)\end{array}$ & $\begin{array}{c}\mathrm{A}_{9} \text { - actual } \\
\left(\mathrm{in}^{2}\right)\end{array}$ \\
\hline 1.2 & 3.75 & 89.92 & 114.51 & 114.51 \\
\hline 1.5 & 5.31 & 90.26 & 138.36 & 138.36 \\
\hline 2.5 & 12.68 & 92.12 & 243.55 & 243.55 \\
\hline 3.0 & 23.47 & 89.86 & 322.37 & 277.59 \\
\hline 3.5 & 40.31 & 72.11 & 399.18 & 277.59 \\
\hline 4.2 & 80.32 & 61.65 & 537.78 & 277.59 \\
\hline
\end{tabular}

\section{Computational Method}

The Reynolds-averaged Navier-Stokes (RANS) solver used in the design and analysis sequence is WIND - Version 5 (Ref. 5), the production flow solver of the NPARC Alliance, a joint code development group of NASA Glenn Research Center, USAF Arnold Engineering Development Center, and the Boeing Company. WIND is a structured-grid finite volume code using upwind numerics for most flow 
applications, and in the current study, the flux difference-splitting technique of Roe was employed to calculate fluxes at cell faces. WIND was used in RANS mode utilizing the Menter Shear Stress Transport (SST) turbulence model (Ref. 6). This model uses a k- $\omega$ formulation in near wall regions, which has been found to produce superior results to other one- and two-equation RANS models as shown by Hamed and Vogiatzis (Refs. 7 and 8). Further, in Ref. 9, it was shown that the Wind code, using the Menter SST turbulence model, could be expected to provide accurate predictions of nozzle internal and external aerodynamics, even at off-design points where flow separations may be present. All computational grids used in this study employed packing to viscous surfaces such that the first point off of the wall corresponded to an average $\mathrm{y}+$ of approximately 1 as is required for proper use with the Menter SST turbulence model. The thermodynamic data in the engine cycle model employed here included real gas effects, but it was determined these data could be represented well by using a specific heat ratio set to 1.2 in the RANS calculations.

\section{Variable Geometry Convergent-Divergent Nozzle}

The first nozzle considered here is an axisymmetric configuration employing a variable convergentdivergent (C-D) internal flowpath with variable throat and exit area. Modern military aircraft utilizing an afterburning engine most frequently use such a C-D nozzle with the variable geometry convergent and divergent sections provided by a flap and seal arrangement. As a result, we refer to the convergent and divergent section flap lengths in the following description of overall C-D nozzle optimization. A schematic of the conceptual integration of the turbine engine and C-D nozzle within the AVBL is shown in Fig. 2.

The aerodynamic layout of the C-D nozzle began with consideration of the divergent section. In order to minimize nozzle divergence losses, it is desirable to set the divergent flaps as long as possible.

However, the overall length of the nozzle could not exceed 26 in. as described previously. Using the Mach 3.5 engine operating point conditions, RANS calculations were used to investigate the variation in uninstalled nozzle performance with divergence angle. Six divergent section lengths were considered, as shown in Table 2 along with the corresponding divergence angle for each case. The convergent flap length was 8 in. for these divergent flap variations. The RANS calculations utilized computational grids having three zones as shown in Fig. 3. One zone was used for each of the following regions: (1) internal nozzle, (2) freestream flow upstream of the nozzle exit, (3) nozzle jet plume and freestream downstream of nozzle exit.

The variation in uninstalled nozzle thrust with divergence angle obtained with the RANS calculations is shown in Fig. 4 with the analytical variation also shown for comparison. This analytical variation in thrust with divergence angle for an axisymmetric nozzle, not considering any viscous or other losses, is equal to $(1+\cos (\theta)) / 2$, as shown in Ref. 10. As expected, the nozzle performance improves with decreasing divergence angle, but this comes at the expense of a longer divergent section and correspondingly heavier nozzle. A divergence angle of 15.11 degrees, corresponding to a flap length of 18 in., was chosen after determining that the marginal improvement in $\mathrm{C}_{\mathrm{fg}}$ with the smallest angle investigated, 13.58 degrees, was not worth the extra weight associated with a longer flap.

Table 2. Nozzle divergent flap angle variation with flap length for Mach 3.5.

\begin{tabular}{|c|c|}
\hline $\begin{array}{c}\text { Divergent Flap Length } \\
\text { (in.) }\end{array}$ & $\begin{array}{c}\text { Divergence Angle, } \\
\theta \text { (Degrees) }\end{array}$ \\
\hline 10.0 & 27.72 \\
\hline 12.0 & 22.90 \\
\hline 14.0 & 19.53 \\
\hline 16.0 & 17.03 \\
\hline 18.0 & 15.11 \\
\hline 20.0 & 13.58 \\
\hline
\end{tabular}

Using the 15.11 degree divergent section, the convergent section length was investigated next and it was found that the convergent section could be shortened to $3.65 \mathrm{in}$. without any reduction in nozzle thrust performance. With the nozzle throat area at a minimum for the Mach 4.2 flight condition, this flap length 
would produce a maximum convergence angle of approximately 35 degrees. With the convergent and divergent section flaps set to $3.65 \mathrm{in}$. and $18 \mathrm{in}$. respectively, a short constant area section ( 2 in.) was added upstream of the convergent flaps to transition from the afterburner to the nozzle. This brought the fully extended nozzle length to 23.65 in. which is well within the initial overall length constraint.

Figure 5 shows the uninstalled thrust coefficient as a function of NPR for the axisymmetric C-D nozzle. The thrust coefficient resulting from a one-dimensional, isentropic expansion to the actual exit area is also shown to quantify the loss due to underexpansion. This curve is also shown with the analytical divergence factor applied to show the loss due to divergence. For the underexpanded nozzle cases, the divergence factor was only applied to the momentum component of thrust as the pressure contribution is unaffected by flow divergence. The remaining loss is attributed to friction and weak shock waves resulting from the use of straight flaps instead of an isentropic contour.

The installed performance of this C-D nozzle, considering the outer AVBL afterbody without control surfaces, was also calculated using RANS CFD with grids having the same topology as those for the uninstalled calculations. It is desirable to set the boattail origin as far forward as possible to reduce the boattail angle and resultant drag. For the nozzle considered here, the boattail was set to start at the same axial station where the afterburner joined the internal nozzle, which is the most forward placement possible without interfering with vehicle control surfaces. A finite thickness equal to approximately 0.1 in. was set for the nozzle trailing edge separating the nozzle exit flow and freestream flow. Mach number contours for the Mach 1.2 (transonic) and Mach 4.2 (maximum) flight conditions are shown in Fig. 6. At Mach 1.2, the exit area is significantly smaller than the AVBL cross sectional area, which results in significant boattail drag. At Mach 4.2 the nozzle exit area is opened to the maximum allowed by the vehicle cross sectional area, and is underexpanded.

The uninstalled and installed performance for the C-D nozzle are compared in Fig. 7. As expected, the boattail drag at Mach 1.2 reduces the installed thrust by approximately 10 percent from the uninstalled thrust. At Mach numbers higher than 2.5, the nozzle is fully open and there is no boattail drag. For all operating points from Mach 1.2 to Mach 2.5, additional RANS calculations were performed in which the nozzle exit area was opened to reduce boattail drag but at the expense of overexpansion. In every case, the maximum installed nozzle performance resulted from setting the nozzle exit area to be 1-D perfectly expanded setting shown in Table 1. For the Mach 4.2 flight condition, the installed thrust is actually slightly higher than the uninstalled thrust. This is due to pressurization of the nozzle trailing edge.

\section{Isentropic Plug Nozzle}

The second nozzle considered here is an isentropic plug nozzle. As discussed in Ref. 10, the plug nozzle offers potential advantages over the C-D nozzle in terms of reduced mechanical complexity and a lower part count. In this study, an isentropic plug is designed, and we compare the thrust performance to that of the C-D nozzle. It has been shown (Ref. 11) that a plug nozzle with an isentropic contour can be expected to provide significantly higher thrust than a simple conical plug shape.

Figure 8 shows important features of the axisymmetric plug nozzle. Supersonic expansion occurs as a result of turning from the throat angle back to the axis of symmetry through an expansion fan centered at the cowl lip. The plug is contoured to provide shock-free flow using Krase's method (Ref. 12). For a given exit area, $\mathrm{A}_{9}$, the throat area, $\mathrm{A}_{8}$, depends on the design NPR. Throat area and NPR cannot be specified independently for this class of external expansion plug nozzles. A circular arc section is used to join the cowl lip to the cylindrical nozzle inlet station. The radius of this arc must be sufficient so as not to restrict the cross-sectional flow area upstream of the throat. An axial translation of 1.15 in. provides the required variation in throat area from the minimum at Mach 4.2 to the maximum at Mach 2.5. For the present design, the cowl lip radius was set to 3.4 in., and a design NPR of 16.5 was used. This resulted in a throat area of $72 \mathrm{in}^{2}$, corresponding to that of the Mach 3.5 flight condition shown in Table 1, and an internal cowl angle of 46 degrees. Throat area variation is accomplished by translating the cowl axially. A circular arc joins the plug contour to a 20 degree half-angle conical section that forms the subsonic portion of the nozzle. This arc must be of sufficient radius to effect the required throat area change. In practice, the conical section used here to represent the subsonic portion of the nozzle would not originate from the nozzle centerline, but instead begin with a rounded forward facing cap positioned at the end of the afterburner. With the nozzle measuring 18.9 in. from the cowl tip to the plug tip in the on-design position, the total nozzle length would be approximately $25 \mathrm{in}$. which is comparable to the length of the C-D nozzle. As discussed in Ref. 10, the plug could be truncated without significant thrust loss. Note that the design 
throat area corresponding to the Mach 3.5 flight condition is between the maximum and minimum values required. However, the design NPR of 16.5 is much lower than the Mach 3.5 value. This is a design compromise resulting from the dependence of $\mathrm{A}_{8}$ on NPR mentioned previously.

The thrust performance of the isentropic plug with translating cowl was investigated using the same RANS procedure described for the C-D nozzle. As shown in Fig. 9, a five zone grid was constructed for each of the operating points with one zone used for each of the following regions: (1) internal nozzle flow up to the end of the constant outer radius, (2) remaining internal nozzle flow up to nozzle throat/exit, (3) nozzle jet region over plug surface into freestream, (4) nozzle freestream upstream of the cowl trailing edge, (5) nozzle jet and freestream downstream of plug tip.

As an initial validation of the plug nozzle design, an inviscid calculation was performed using the design NPR and throat area. For this calculation, the grid zone upstream of the cowl trailing edge was not used. The Mach 3.5 freestream was applied uniformly to an inflow plane at the cowl trailing edge to avoid boattail effects. Mach number contours for this inviscid design validation case are provided in Fig. 10. It may be observed that the nozzle jet does expand in a very nearly isentropic manner over the plug surface. Further, the thrust coefficient was 0.998 which verifies that the nozzle design is nearly shock free at the design conditions.

Following this validation, RANS calculations were obtained for all of the engine operating points in Table 1. Mach number contours for the Mach 1.2 (transonic) and Mach 4.2 (maximum) flight conditions are shown for the plug nozzle in Fig. 11. At Mach 1.2, it may be observed that the nozzle is operating significantly overexpanded with flow separation region near the end of the plug. At Mach 4.2, the flow expands efficiently over the plug and there is no evidence of any separation. The nozzle is underexpanded, but as with the C-D nozzle, it is not possible to perfectly expand the nozzle flow at the highest flight Mach numbers. The expansion around the boattail may be clearly observed for each case.

The uninstalled and installed thrust performance of the plug nozzle are compared to those of the C-D nozzle in Figs. 12 and 13 respectively. The C-D nozzle provides the highest uninstalled thrust at the low and high end NPR settings while the plug nozzle provides the highest uninstalled thrust at the intermediate NPR settings near the design NPR of 16.5. The plug nozzle experiences a larger boattail drag due to the 46 degree cowl angle. At the lowest flight Mach number points investigated, Mach 1.2 and 1.5, the C-D nozzle provides significantly higher installed thrust than the plug nozzle. At the higher flight Mach numbers, the performance of the two nozzles is similar.

\section{Conclusions}

The aerodynamic designs of two exhaust nozzles intended for use with an afterburning engine on a vehicle with an accelerating flight profile to Mach 4.2 have been completed. The first was a C-D nozzle with variable throat and exit area and the second was an isentropic plug nozzle with variable throat area provided by a translating cowl. Using RANS CFD, the thrust performance of the two nozzles was calculated for flight conditions from Mach 1.2 to Mach 4.2.

The uninstalled performance of the C-D nozzle was significantly higher than the plug nozzle at Mach 1.2 and 1.5 due to the fixed $\mathrm{A}_{9}$ of the plug nozzle. The plug nozzle produced the highest uninstalled thrust from Mach 2.5 to Mach 3.5, and the C-D nozzle was slightly higher at the maximum flight speed of Mach 4.2. The installed thrust performance of the C-D nozzle was higher than that of the plug at all Mach numbers with the greatest difference at the lower supersonic points. Boattail drag degraded the installed performance by over 10 percent at Mach 1.2 for both nozzle configurations. The boattail drag of the C-D nozzle decreased with Mach number more rapidly than the plug nozzle because as the C-D nozzle divergent section opened with increasing Mach number, the boattail angle decreased. In contrast, the cowl angle for the plug nozzle is fixed for all Mach numbers.

Despite the higher installed performance of the C-D nozzle, mechanical, thermal, and structural factors would need to be considered in overall system studies in order to make the optimal selection. The plug nozzle would likely be lighter and less mechanically complex than the C-D nozzle but may require additional cooling for the plug and attachment struts. In addition, the full length isentropic plug considered here could be truncated to reduce nozzle length and weight without significant loss in installed thrust. 


\section{Acknowledgments}

This work was sponsored by the Office of Naval Research, Code 351 (Mr. Lawrence Ash, Program Manager), and NASA Glenn Research Center. The work is relevant to high-speed turbine vehicles for use in Time Critical Strike, and to the Next Generation Launch Technology (NGLT) Revolutionary Turbine Accelerator (RTA) Project.

\section{References}

1. Shafer, D.G. and McNelis, N.B., "Development of a Ground Based Mach 4+ Revolutionary Turbine Accelerator Technology Demonstrator (RTATD) for Access to Space," ISOABE Paper 2003-1125, 2003.

2. Hagemann, G., Immich, H., and Terhardt, M., "Flow Phenomena in Advanced Rocket Nozzles The Plug Nozzle," AIAA Paper 98-3522, July 1998.

3. Rommel, T., Hagemann, G., Schley, C.A., Krulle, G., and Manski, D., "Plug Nozzle Flowfield Analysis," Journal of Propulsion and Power, Vol. 13, No. 5, 1997, pp. 629-634.

4. Hagemann, G., Schwane, R., Reijasse, P., and Ruf, J., "NASA RTO WG 10: CFD Results of Plug Nozzle Test Cases," AIAA Paper 2002-4036, July 2002.

5. Nelson, C.C. and Power, G.D., "CHSSI Project CFD-7: The NPARC Alliance Flow Simulation System," AIAA Paper 2001-0594, Jan. 2001.

6. Menter, F.R., "Two-Equation Eddy-Viscosity Turbulence Models for Engineering Applications," AIAA Journal, Vol. 32, No. 8, Aug. 1994, pp. 1598-1605.

7. Hamed, A. and Vogiatzis, C., "Overexpanded Two-Dimensional Convergent-Divergent Nozzle Flow Simulations, Assessment of Turbulence Models," Journal of Propulsion and Power, Vol. 13, No. 3, 1997, pp. 444-445.

8. Hamed, A. and Vogiatzis, C., "Overexpanded Two-Dimensional Convergent-Divergent Nozzle Performance, Effects of Three-Dimensional Flow Interactions," Journal of Propulsion and Power, Vol. 14, No.2, 1998, pp. 234-240.

9. DalBello, T., Georgiadis, N.J., Yoder, D.A., and Keith, T.G., "Computational Study of Axisymmetric Off-Design Nozzle Flows,” AIAA Paper 2004-0530, Jan. 2004.

10. Stitt, L.E., "Exhaust Nozzles for Propulsion Systems With Emphasis on Supersonic Cruise Aircraft," NASA RP 1235, May 1990.

11. Ito, T., Fujii, K., and Hayashi, A.K., "Computations of Axisymmetric Plug-Nozzle Flowfields: Flow Structures and Thrust Performance," Journal of Propulsion and Power, Vol. 18, No. 2, 2002, pp. 254-260.

12. Graham, A.R., "NASA Plug Nozzle Handbook,” NASA CR 117018, Jan. 1966. 


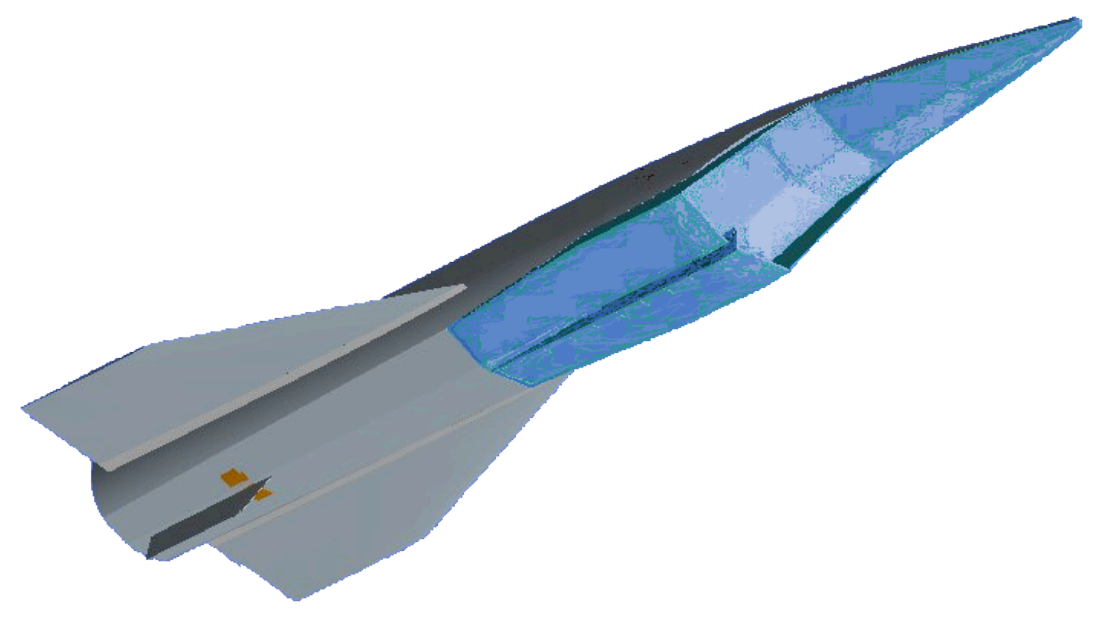

Fig. 1. Conceptual drawing of the Air-Vehicle Baseline (AVBL) Configuration.

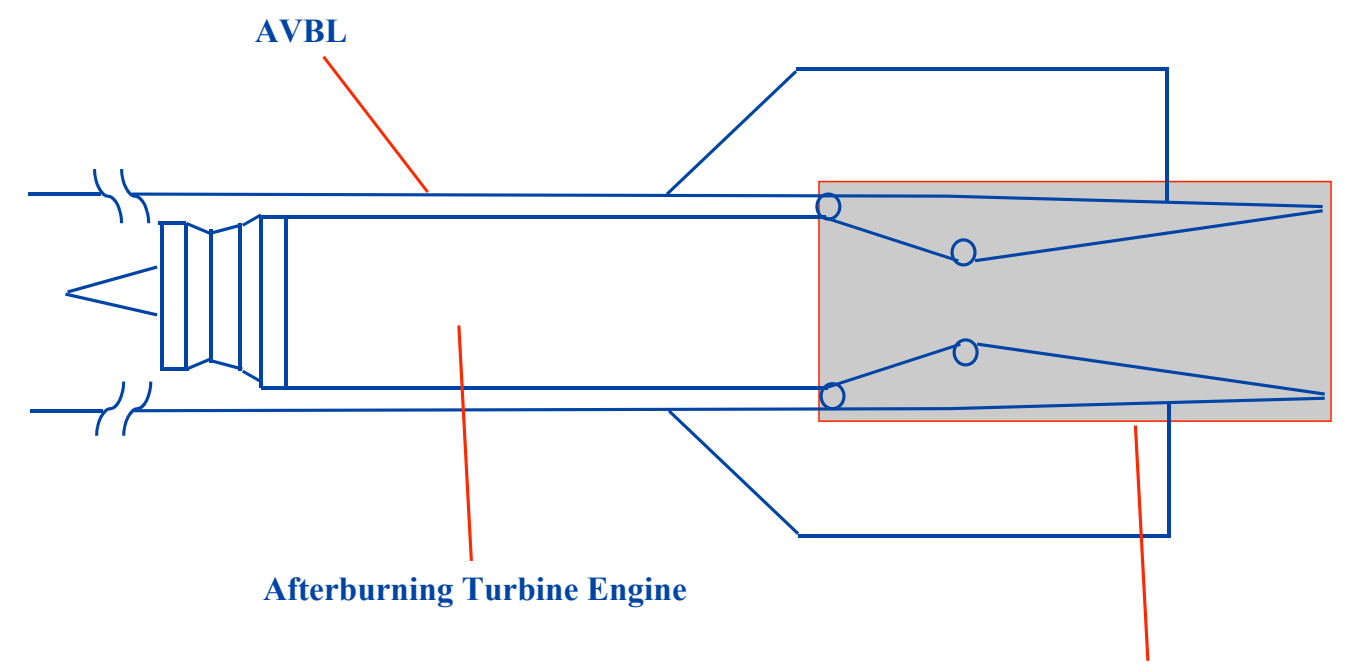

Axisymmetric Convergent-Divergent Nozzle

Fig. 2. Schematic of the AVBL engine/nozzle integration.

American Institute of Aeronautics and Astronautics 


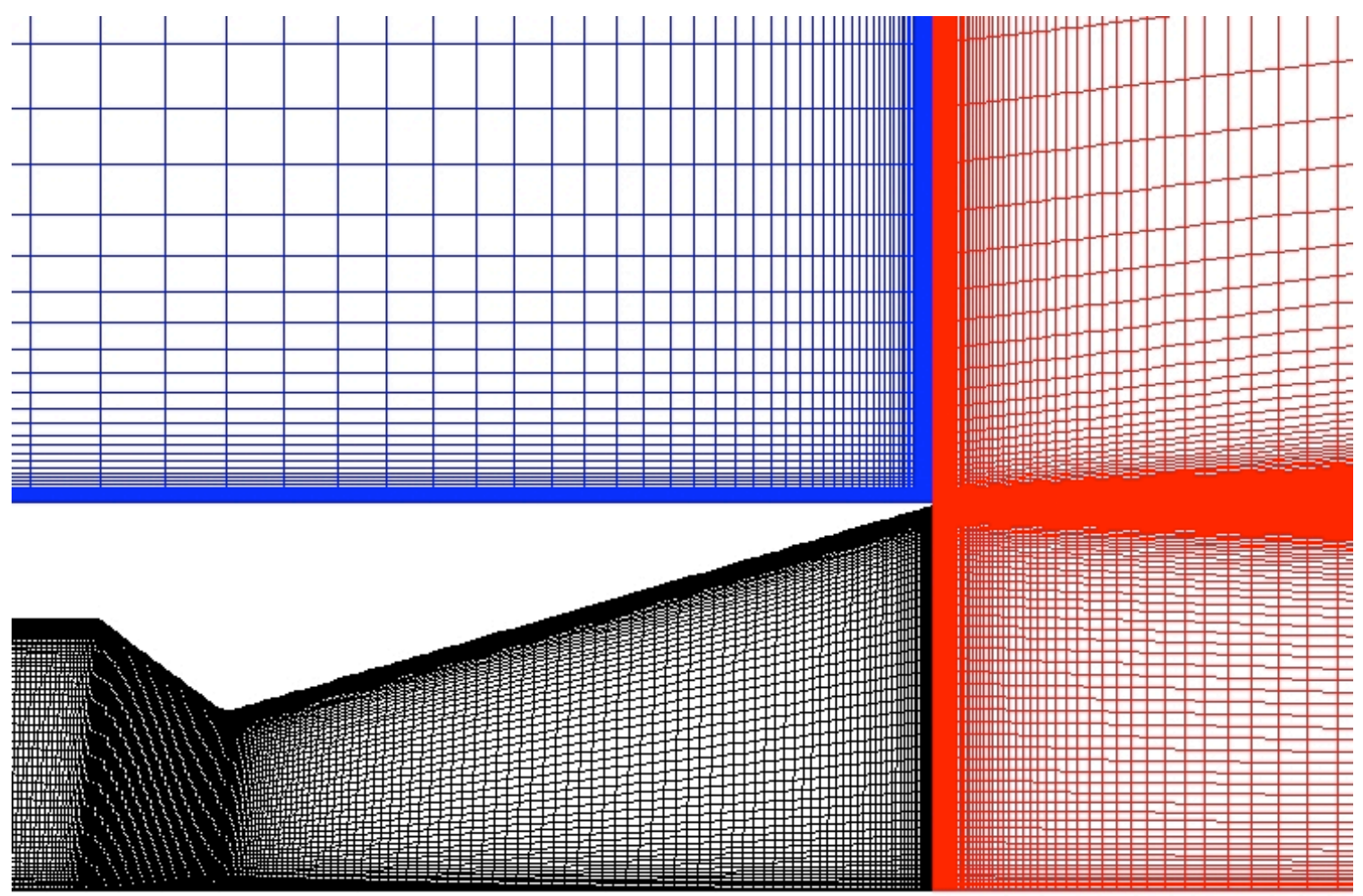

Fig. 3. Computational grid for axisymmetric C-D nozzle for Mach 4.2 flight configuration (region near nozzle shown). 


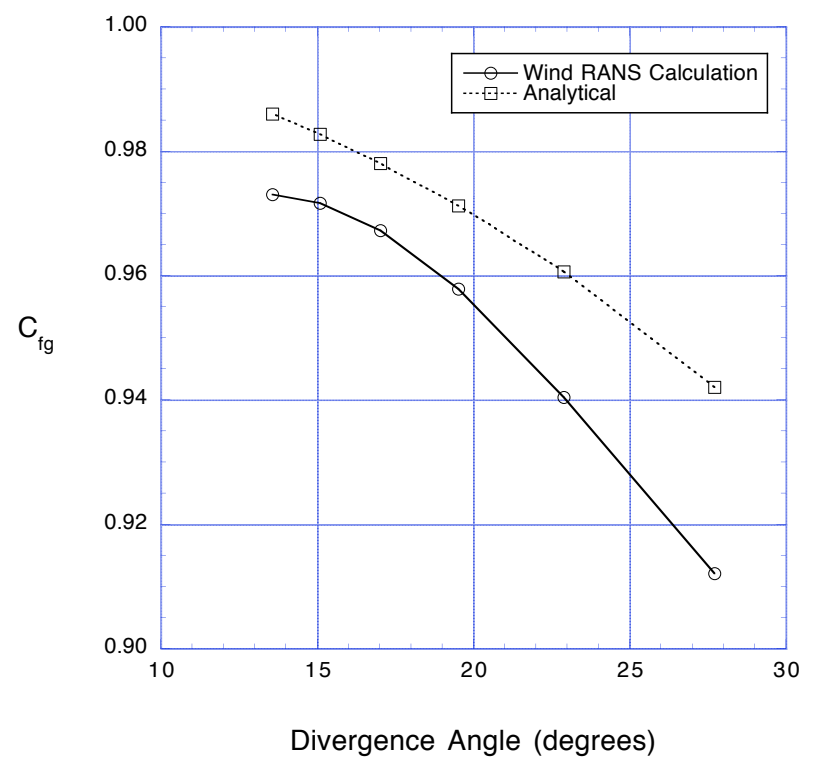

Fig. 4. Variation of internal nozzle performance with divergence angle.

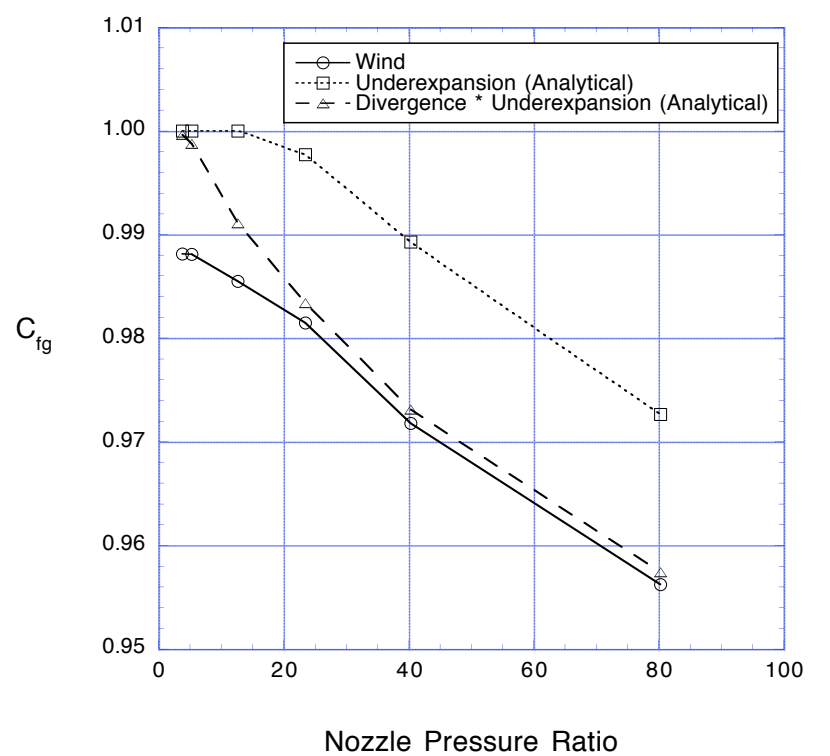

Fig. 5. Uninstalled performance for the axisymmetric C-D nozzle.

American Institute of Aeronautics and Astronautics 


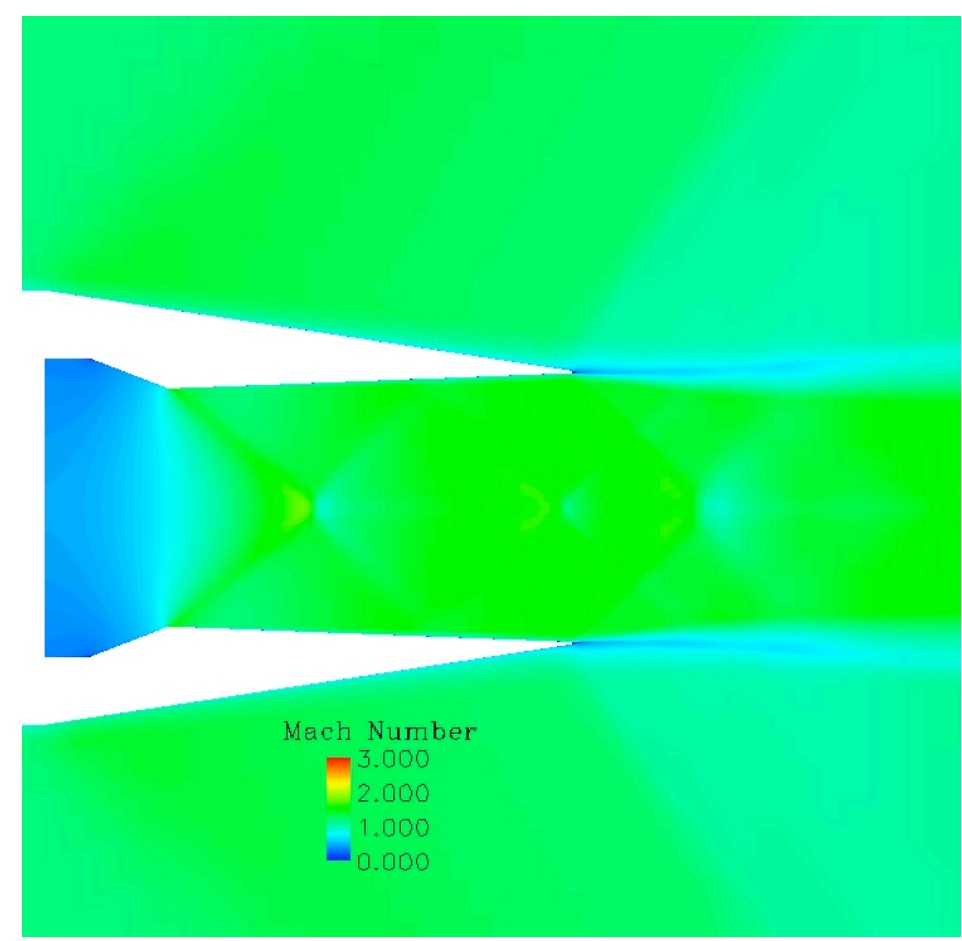

(a) Mach 1.2

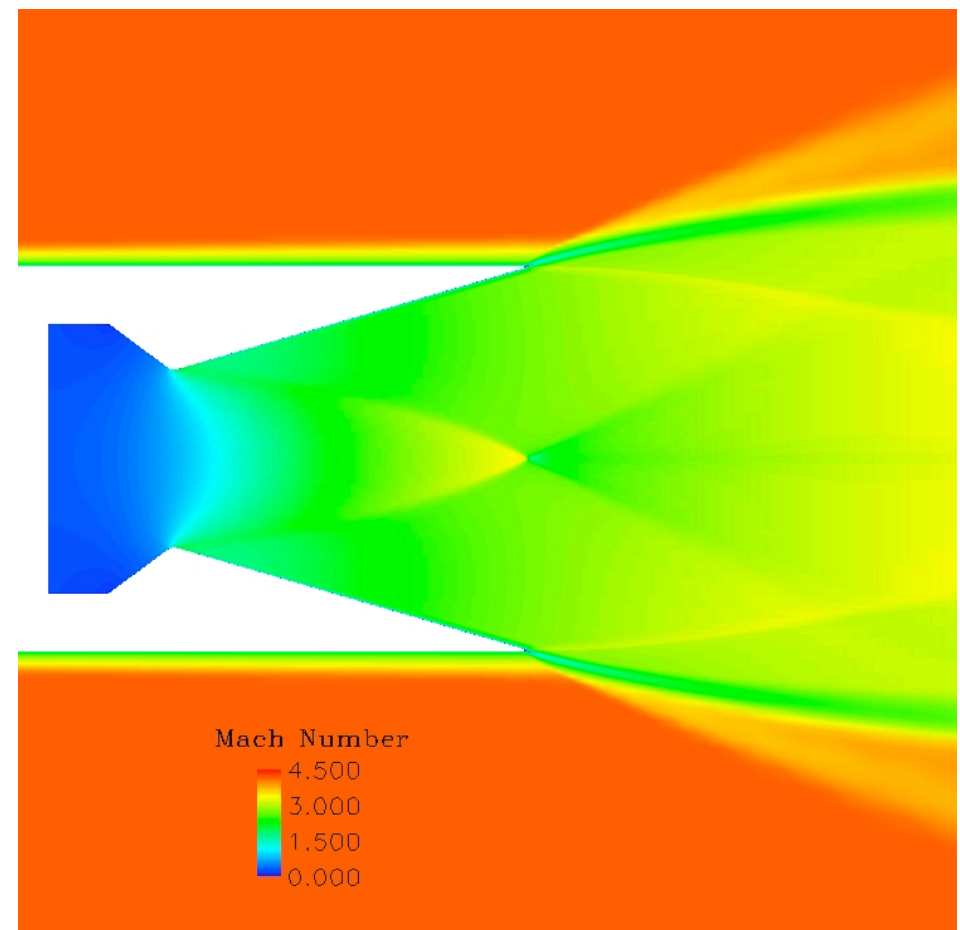

(b) Mach 4.2

Fig. 6. Mach number contours for the installed C-D nozzle configuration. 


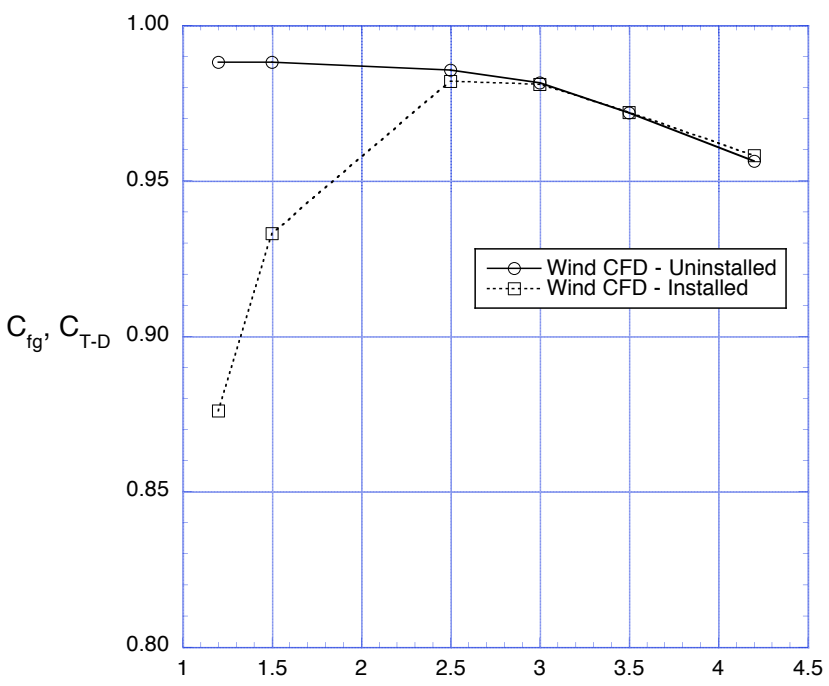

Freestream Mach Number

Fig. 7. Comparison of uninstalled and installed performance for the C-D nozzle.

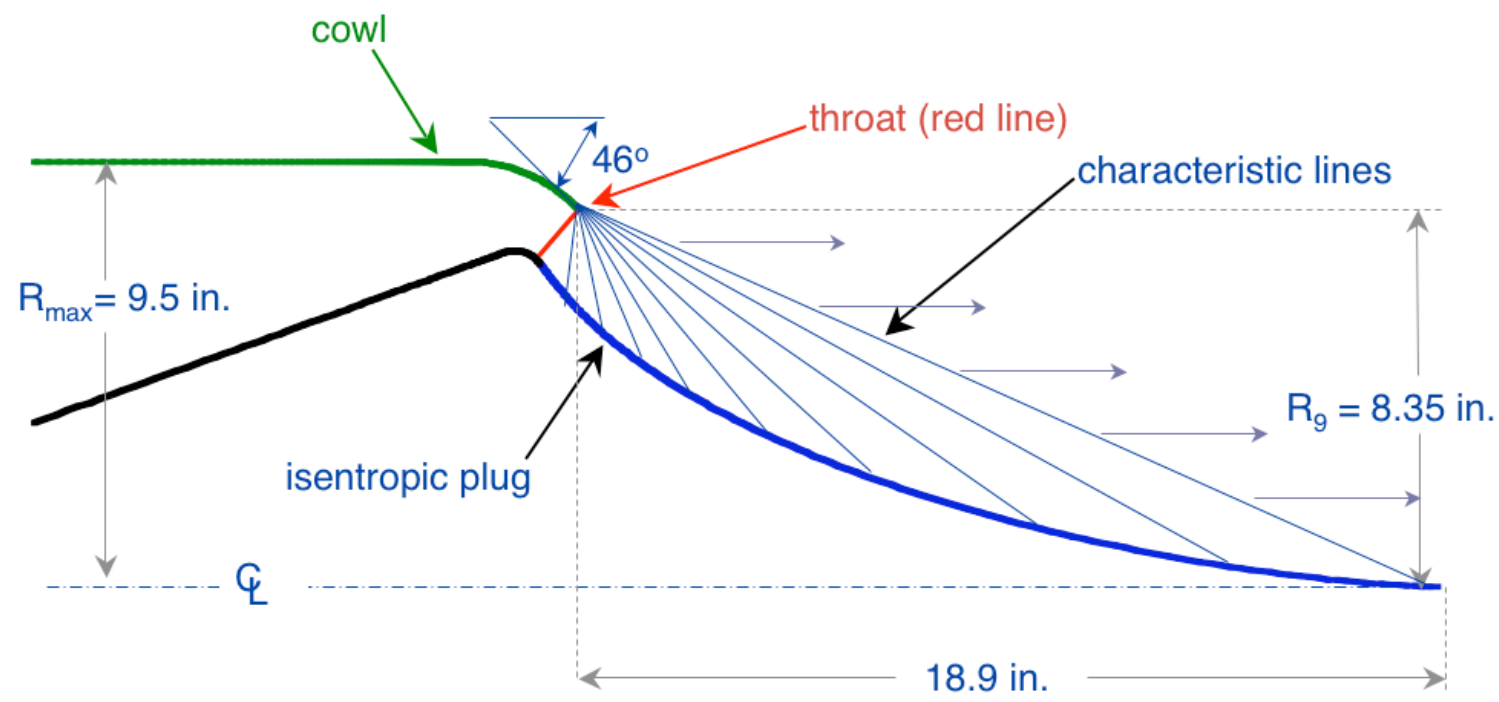

Fig. 8. Isentropic plug nozzle schematic. 


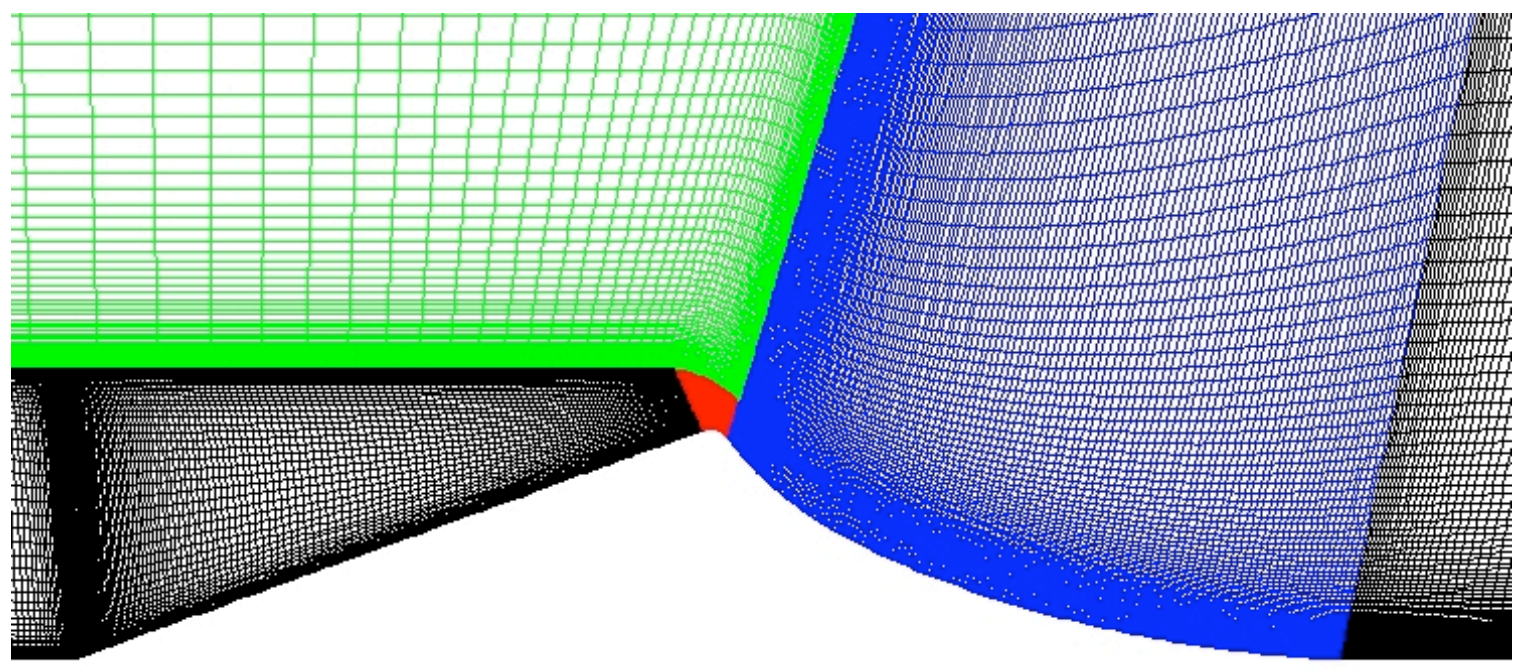

Fig. 9. Computational grid for isentropic plug nozzle for Mach 4.2 flight configuration (region near nozzle shown).

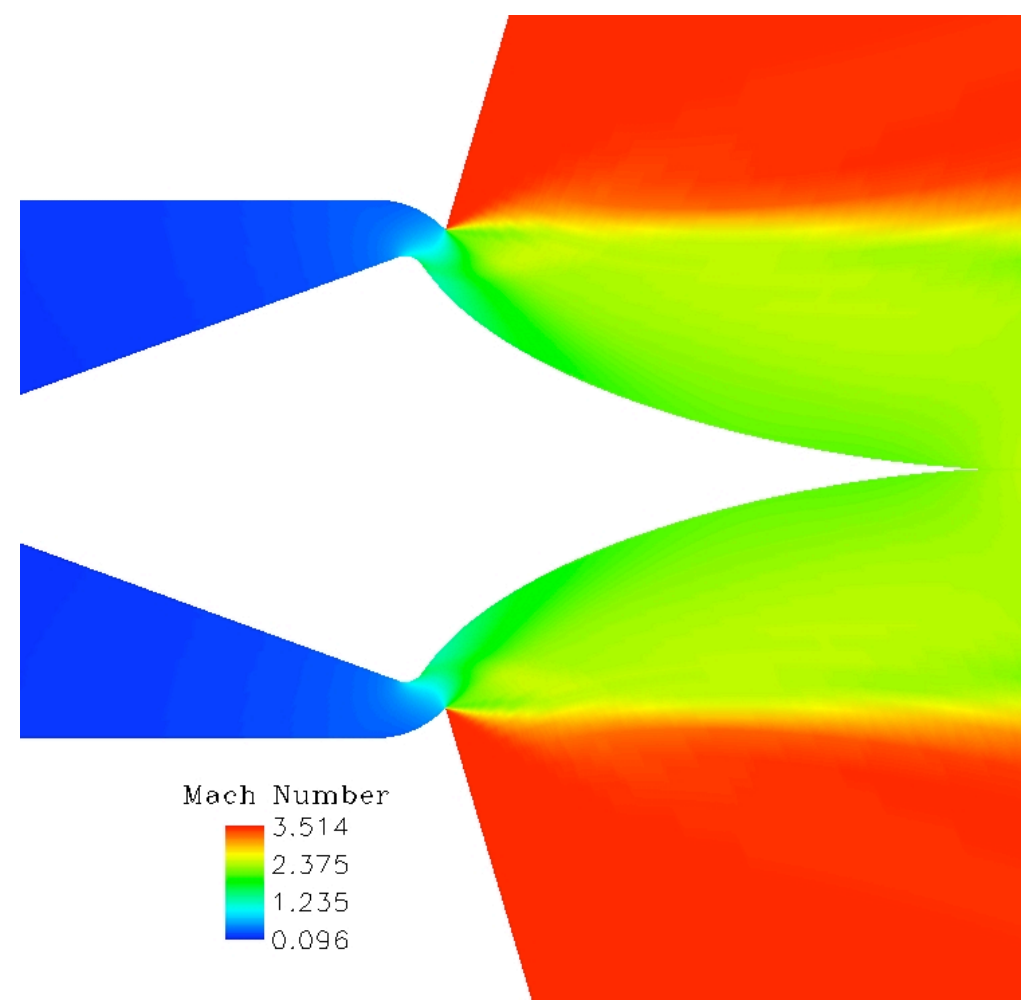

Fig. 10. Mach number contours for inviscid nozzle calculation at design nozzle pressure ratio. 


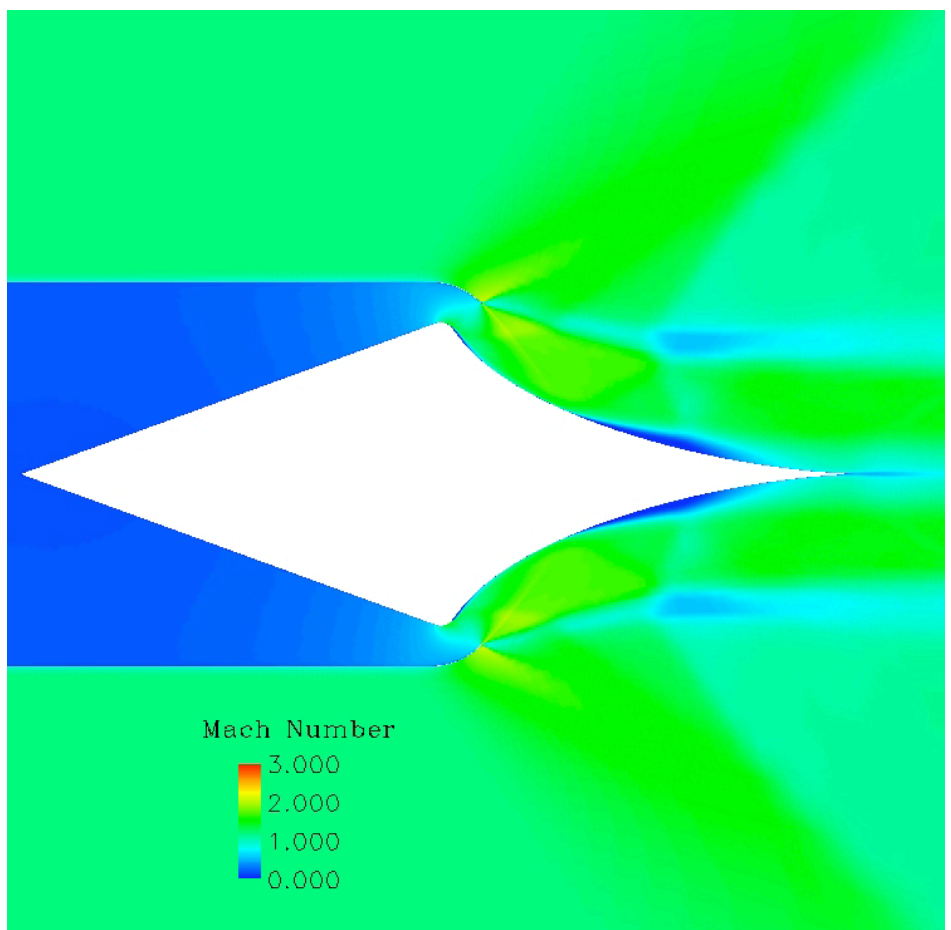

(a) Mach 1.2

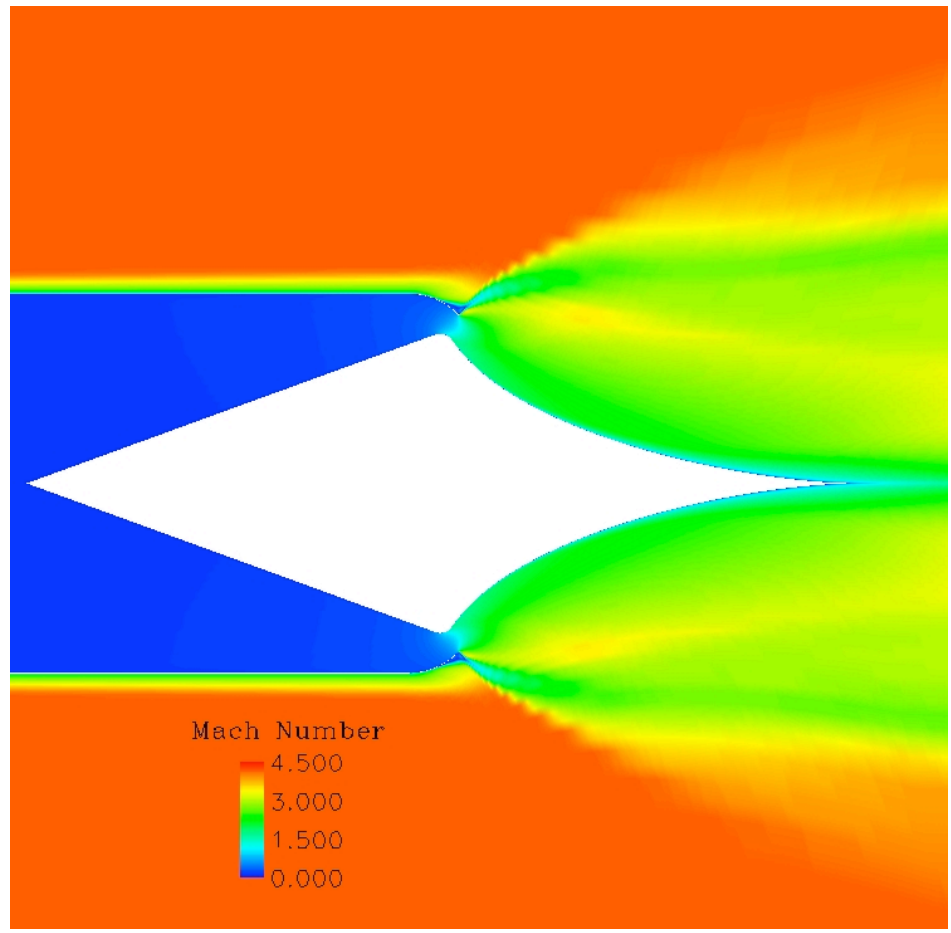

(b) Mach 4.2

Fig. 11. Mach number contours for the plug nozzle configuration. 


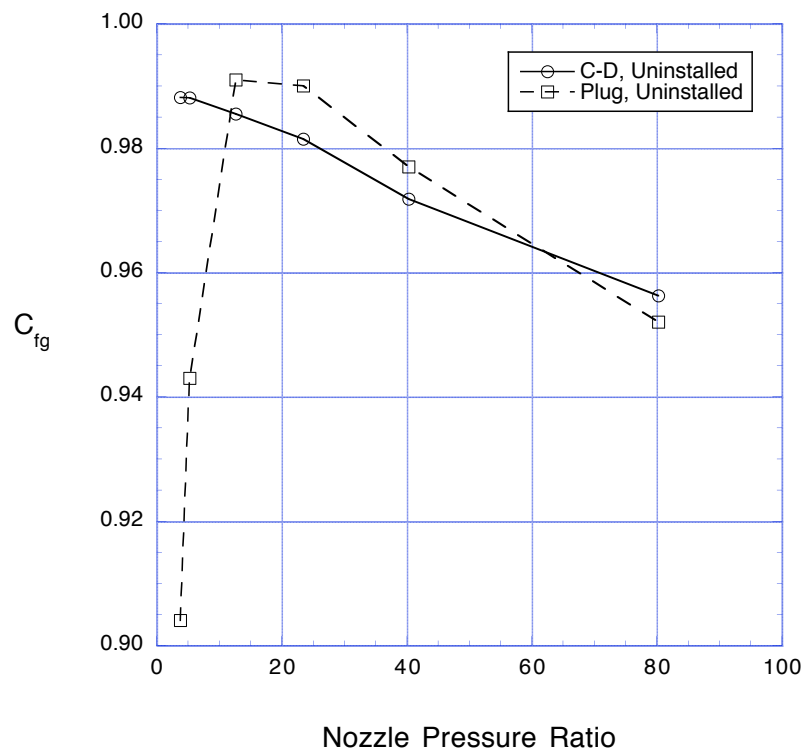

Fig. 12. Comparison of uninstalled performance for the $C-D$ and plug nozzles.

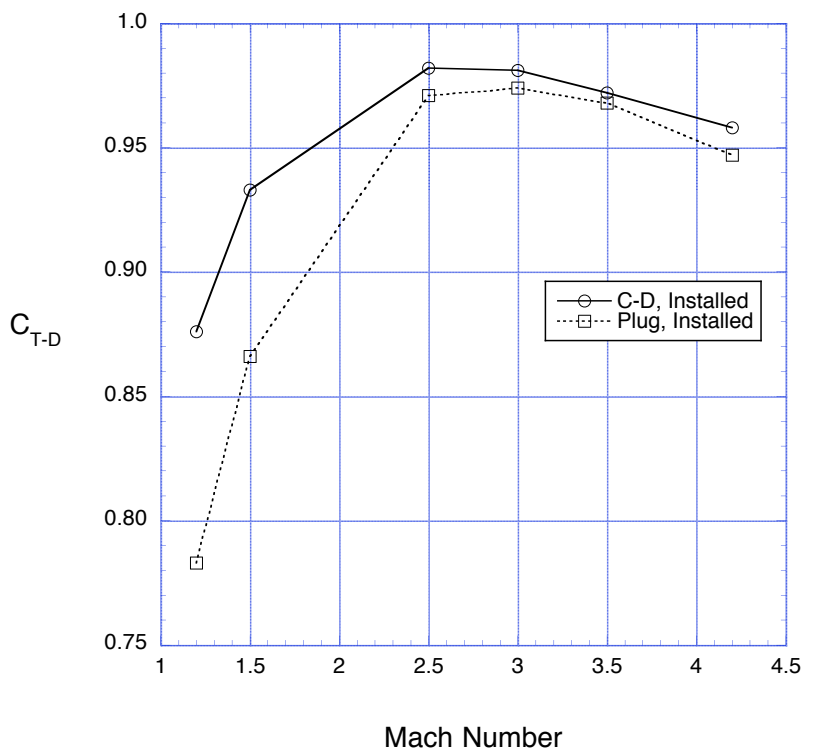

Fig. 13. Comparison of installed performance for the $C$-D and plug nozzles.

American Institute of Aeronautics and Astronautics 